\title{
COMMENTARY
}

\section{Worst case: rethinking tertiary triage protocols in pandemics and other health emergencies}

\author{
Sheri L Fink* \\ See related research by Christian et al., http://ccforum.com/content/13/5/R170
}

\begin{abstract}
Demand for critical care resources could vastly outstrip supply in an influenza pandemic or other health emergency, which has led expert groups to propose altered standards for triage and resource allocation. A pilot study by Christian and colleagues applied the Ontario, Canada draft critical care triage protocol to an actual retrospective cohort of intensive care unit patients. The findings are troubling. Patients who would have been triaged to expectant and designated for withdrawal of intensive care unit care and ventilator support in fact had substantial survival rates. Triage officers often disagreed and lacked confidence in their categorization decisions. These findings suggest that rationing paradigms which include categorical exclusion criteria and withdrawal of lifesaving resources should be reconsidered, and public input sought on nonclinical aspects.
\end{abstract}

Several groups in Canada and the US have recently pondered disastrous scenarios where demand for hospital admission and critical care resources would vastly outstrip supply in an influenza pandemic or other health emergency. Rather than leave wrenching prioritization decisions to exhausted, frontline health professionals, the groups have proposed algorithms that would be used to triage patients and to allocate - and even reallocate lifesaving resources.

Questions have been raised about the ability of physicians to implement these proposals, however, which in some cases call for categorically excluding groups of patients from needed care and withdrawing life support regardless of the wishes of patients or their proxies.

*Correspondence: Sfink@hsph.harvard.edu

Harvard Humanitarian Initiative, Harvard University, 14 Story Street, $2^{\text {nd }}$ Floor, Cambridge, MA 02138, USA
Evidence that these protocols would accurately predict which patients are likely or unlikely to survive, and to direct resources accordingly, has also been insufficient.

A pilot study by Christian and colleagues tackles some of these questions by examining the results of applying Ontario's draft critical care triage protocol to an actual cohort of intensive care unit (ICU) patients [1]. One-half of the pilot study's authors were original authors of the Ontario protocol [2]. In the US and in Canada, many governmental bodies, hospitals, and the US Veterans Health Administration have incorporated aspects of the Ontario protocol into pandemic planning documents.

The study's results are troubling. Patients who would have been triaged to expectant and designated for withdrawal of ICU care and ventilator support in fact had substantial survival rates. Triage officers often disagreed and lacked confidence in their categorization decisions. The findings suggest that rationing paradigms which include categorical exclusion criteria and withdrawal of lifesaving resources may need to be rethought, and public input sought on nonclinical aspects.

The Ontario protocol was successful by one measure. Patients who would have been excluded from ICU admission in a pandemic had significantly lower rates of survival than other patients when they received standard treatments.

A full one-quarter of these patients, however, survived their hospital stays. The rate of survival was higher still among groups of patients who would have failed the protocol's ventilator time trials. For example, more than $70 \%$ of those who would have been triaged to expectant after a 5-day ICU time trial and would have been designated for terminal extubation or ICU discharge actually survived with continued treatment. Paradoxically, under the triage algorithm their ventilators could have been reassigned to newly admitted, intermediate treatment priority patients whose rate of survival was lower $(62.5 \%)$.

Many of the days of ventilation made available through the use of the protocol were thus made available by denying or removing them from patients who would have 
benefited. The study fails to account for these patients' deaths explicitly in its discussion of the protocol's ability to increase resource availability.

For example, the authors use 'rates from the first wave of H1N1 in Canada' to contend that the protocol could have saved 50 lives 'based upon the 568 days of ventilation made available ... assuming an average of 10 days of ventilation and an $89 \%$ survival rate' [1].

The data do not, however, support this prediction. The calculation does not subtract for $\mathrm{H} 1 \mathrm{~N} 1$ survivors who would have probably died after being either excluded from ICU care - comorbidities described in these patients suggest many would have been [3] - or withdrawn from treatment under the Ontario protocol guidelines. The fact that most of the critically ill H1N1 patients had acute respiratory distress syndrome and a long ICU course suggests that, in many of them, Sequential Organ Failure Assessment scores would not have improved after 48 or 120 hours. Many patients would therefore probably have fallen into the protocol's blue category (for example, Sequential Organ Failure Assessment score $<8$ and no change at 120 hours) and would have been terminally extubated.

This raises the specter of wave after wave of acute respiratory distress syndrome patients being put on ventilators for 2 to 5 days only to be extubated before they improve. One could envision a greater loss of life using the triage tool, which the study's triage officers were instructed to consider as the standard of care, compared with using another approach that did not involve extubation. Many draft pandemic triage plans in the US include reassessment tools that are similar to those of Ontario.

Further, the calculation of lives saved does not subtract for the deaths of 30 patients who would have been excluded or withdrawn from needed treatment under the protocol, but who actually survived in the real world. Also, the days of ventilation made available by excluding these patients would not necessarily be contiguous for each new H1N1 patient or available in the ideal way assumed by the calculation. Further, first-wave H1N1 survivors in Canada required a median of 12 days (not 10 days) of ventilation, and overall survival in the critically ill was $83 \%$ (not $89 \%$ ) [3].

The pilot study also hints at the excruciating difficulties clinicians would have faced in implementing the protocol. Although three of four triage officers in the study were involved in drafting the original triage instrument, considerable inter-officer disagreement and lack of confidence in triage decisions were noted. In a situation where triage decisions carry life and death stakes, and family members vent their anguish, these difficulties will be heightened.

For example, in one isolated New Orleans hospital after Hurricane Katrina [4], family members objected when clinicians assigned patients with Do Not Resuscitate orders the lowest evacuation priority. Several altered standard protocols, although not that of Ontario, use Do Not Resuscitate status as an exclusion criterion for hospital admission in a pandemic; an expert panel convened by the US Institute of Medicine recently recommended against using Do Not Resuscitate status in this way [5].

To date, rationing protocols for pandemics have been developed like Ontario's, by expert panels with great effort and intentions but without significant input from the general public. Triage decision-making algorithms, unlike evidence-based guidelines for disease treatment, are shaped by many nonclinical considerations. Medical experts and the lay public may have different views about what ethical principles and values should guide triage priorities (the role of age, chronic illness, disability, and previous access to care are but a few examples); this cannot be known unless those developing guidelines find ways to engage the public [6].

Some authors and an ethics advisory subcommittee to the director of the Centers for Disease Control and Prevention have suggested algorithms that prioritize patients along a scale with a sliding cutoff point rather than categorically excluding certain groups; patients who are assigned a low priority would then be provided treatment if it becomes available $[7,8]$. In the days after Hurricane Katrina, certain patients triaged to the lowest priority category were not evacuated even after resources became available to do so, suggesting the need to emphasize situational awareness and for frequent reassessment in triage protocols.

Ultimately the use of even the best survivorship prediction tool may need to be leavened by individual clinician judgment and be weighed against factors such as fairness, the effect on public trust, and mental distress caused to triage officers, clinicians, patients, and family members. The pilot study by Christian and colleagues lights the way for future work.

\section{Abbreviations}

$\mathrm{ICU}=$ intensive care unit.

Competing interests

The author declares that they have no competing interests.

Published: 21 January 2010

\section{References}

1. Christian MD, Hamielec C, Lazar NM, Wax RS, Griffith L, Herridge MS, Lee D, Cook DJ: A retrospective cohort pilot study to evaluate a triage tool for use in a pandemic. Crit Care 2009, 13:R170.

2. Christian MD, Hawryluck L, Wax RS, CookT, Lazar NM, Herridge MS, Muller MP, Gowans DR, Fortier W, Burkle FM: Development of a triage protocol for critical care during an influenza pandemic. CMAJ 2006, 175:1377-1381.

3. Kumar A, Zarychanski R, Pinto R, Cook DJ, Marshall J, Lacroix J, Stelfox T, Bagshaw S, Choong K, Lamontagne F, Tergeon AF, Lapinsky S, Ahern SP, Smith O, Siddiqui F, Jouvet P, Khwaia K, McIntryre L, Menon K, Hutchison J, Hornstein D, Joffe A, Lauzier F, Singh J, Karachi T, Wiebe K, Olafson K, Ramsey C, Sharma S, Dodek P, Meade M, Hall R, Fowler RA; Canadian Critical Care Trials Group 
H1 N1 Collaborative: Critically ill patients with 2009 influenza A (H1N1) infection in Canada. JAMA 2009, 302:1872-1879.

4. Fink SL: The deadly choices at memorial. In New York Times Magazine; 30 August 2009:28-46.

5. Altevogt BM, Stroud C, Hanson SL, Hanfling D, Gostin LO (eds): Guidance for Establishing Crisis Standards of Care for Use in Disaster Situations: A Letter Report. Washington, DC: National Academies Press; 2009.

6. Department of Health, Seattle and King County: Public Engagement Project on Medical Service Prioritization During an Influenza Pandemic. Seattle, WA: Public Health - Seattle \& King County; 29 September 2009 [http://s3.amazonaws. com/propublica/assets/docs/seattle_public_engagement_project_final_ sept2009.pdf].
7. White DB, Katz MH, Luce JM, Lo B: Who should receive life support during a public health emergency? Using ethical principles to improve allocation decisions. Ann Intern Med 2009, 150:132-138.

8. Fink, S: Your chance to weigh in on ventilator rationing for a severe flu pandemic. ProPublica [http://www.propublica.org/feature/ ventilator-rationing-for-a-severe-flu-pandemic-1122]

doi:10.1186/cc8216

Cite this article as: Fink SL: Worst case: rethinking tertiary triage protocols in pandemics and other health emergencies. Critical Care 2010, 14:103. 